Check for updates

Hurley Group, London

clare.gerada@nhs.net Follow Clare on Twitter: @ClareGerada Cite this as: BMJ 2021;374:n1917 http://dx.doi.org/10.1136/bmj.n1917 Published: 03 August 2021
WOUNDED HEALER

\section{Clare Gerada: Happy birthday, NHS}

\section{Clare Gerada GP partner}

On 5 July 2021 the NHS had its 73rd birthday. To mark this occasion, I-along with others drawn from the health, social care, and voluntary sectors, as well as patients, carers, and scientists-attended a service of commemoration and thanksgiving at St Paul's Cathedral. On the day, the NHS was also honoured with a George Cross from the Queen in recognition of how the organisation, and of course all of those who have worked in it, have served this country since 1948.

The NHS is a remarkable achievement, which despite its problems continues to do (almost) what it set out to do at the start: provide care, free at the point of use, irrespective of people's ability to pay. I started working in south London when the NHS had just reached its 40th birthday. I had taken over from a GP who herself had worked in the practice from before the start of the NHS. Patients at that time still referred to me as their "panel” doctor-a reference to the National Insurance Act 1911, precursor to the NHS, when Britain's industrial workers (but, sadly, because of opposition from the BMA, not their dependants) were insured to be on the list, or panel, of a GP.

John Fry, a founding member of the Royal College of General Practitioners and GP in south London, wrote years later that on 5 July 1948 "there were no celebrations, no bands or public processions." He had "the same premises, same patients, same arrangements for consultations and home visits and with the same part time staff, my wife."1

But there was a big difference. No patients now needed to feel embarrassed or fearful about the costs of their care, while Fry and thousands of other doctors throughout the UK no longer had to worry that they might not get paid.

The demand for care in 1948, as now, was immense because patients had waited for years to have their conditions dealt with. Back then, it was through years of sacrifice and neglect; now it is through the ravages of the covid-19 pandemic and the backlog of work that it has created. But, as we did in St Paul's Cathedral, we must all celebrate.

The NHS is truly a remarkable institution, one that we should all be proud of. It has rightly been awarded the honour it richly deserves. Furthermore, it is a testament to NHS England's outgoing chief executive, Simon Stevens, who has led us through the most difficult of times, that the NHS, while battered and bruised, has nevertheless survived the stormy waters of this pandemic. Happy birthday, NHS-and thank you, good luck, and goodbye, Simon.

Competing interests: See www.bmj.com/about-bmj/freelance-contributors.

Provenance and peer review: Commissioned; not externally peer reviewed.

Clare Gerada is chair of Doctors in Distress and medical director of NHS Practitioner Health. Her book, Beneath the White Coat: Doctors, their Minds and Mental Health, is published by Routledge and can be purchased at https://www.routledge.com/Beneath-the-White-Coat-Doctors-Their-Minds-and-Mental-Health/Gerada/p/book/9781138499737. All royalties will be donated to Doctors in Distress.

1. Fry J. General practice and primary care 1940s-1980s. Nuffield Provincial Hospitals Trust, 1988. 